\title{
O DISCURSO DAS PESSOAS COM DEFICIÊNCIA FÍSICA SOBRE A PRÓPRIA SEXUALIDADE
}

\author{
EL DISCURSO DE LAS PERSONAS CON DISCAPACID FÍSICA SOBRE \\ LA PROPIA SEXUALIDAD
}

\author{
THE DISCOURSE OF PEOPLE WITH PHYSICAL DISABILITY \\ ABOUT THE OWN SEXUALITY
}

\author{
Calixto Júnior de SOUZA ${ }^{1}$ \\ Fátima Elisabeth DENARI ${ }^{2}$ \\ Maria da Piedade Resende da COSTA ${ }^{3}$
}

RESUMO: Partindo do pressuposto que a sexualidade das pessoas com deficiências é vista como tabu, este estudo tem como norte compreender como se constitui a instalação desses tabus e mitos à luz da área de educação especial. Este estudo, portanto, tem como intenção analisar o discurso das pessoas com deficiências físicas com lesão medular sobre a temática de sexualidade, almejando compreender a expressão de sexualidade. Para tanto, a metodologia deste estudo se caracteriza por possuir um tipo de pesquisa descritiva e se materializa por meio da coleta de dados de um roteiro de entrevista via Skype das pessoas envolvidas. Constata-se que esta temática é pouco explorada, possuindo poucos estudos que tratam sobre a sexualidade. Conclui-se, então, que as pessoas com deficiência física tiveram uma percepção positiva da expressão da sexualidade, denotando que querem ser vistas como pessoas sem qualquer limitação e, acima de tudo, que estão preparadas para romper os tabus que circunscrevem suas relações afetivas e sociais.

PALAVRAS-CHAVE: Educação especial. Deficiência física. Sexualidade.

RESUMEN: Suponiendo que la sexualidad de las personas con discapacidad es visto como un tabú, este estudio es entender cómo es la instalación de estos tabúes y mitos a la luz de la educación especial. Este estudio, por lo tanto, se pretende analizar el discurso de las personas con discapacidad con lesión medular en el tema de la sexualidad, con el objetivo de comprender la sexualidad de expresión. Por isto, la metodología de este estudio se caracteriza por tener un tipo de investigación descriptiva y se materializa mediante la colección de datos de una entrevista estructurada a través de Skype a las personas involucradas. Se hace notar que este tema está poco explorada, que hay pocos estudios que tienen que ver con la sexualidad. Concluye, entonces, que las personas con discapacidad tienen una percepción positiva

\footnotetext{
${ }^{1}$ Universidade Federal de São Carlos (UFSCar), São Carlos - SP - Brasil. Doutorando em Educação Especial. E-mail: calixtojr_ufg@yahoo.com.br.

${ }^{2}$ Universidade Federal de São Carlos (UFSCar), São Carlos - SP - Brasil. Professora Associada. Centro de Educação e Ciências Humanas. E-mail: fadenari@terra.com.br.

${ }^{3}$ Universidade Federal de São Carlos (UFSCar), São Carlos - SP - Brasil. Professora Doutora no Centro de Educação e Ciências Humanas. E-mail: mariadapiedadecostac@ gmail.com.
} 
de la expresión de sexualidad, lo que denota que quieren ser vistos como personas sin ningún tipo de limitación y, sobre todo, que están preparados para romper los tabúes que limitan sus relaciones emocionales y social.

PALABRAS CLAVE: La educación especial. Deficiencia física. La sexualidad.

ABSTRACT: On the assumption that the sexuality of people with disabilities is seen as taboo, this study is to understand how the installation of these taboos and myths in the area of special education. This study, therefore, is intended to analyze the speech of people with physical disabilities with spinal cord injury on sexuality theme, aiming to analyze the expression of sexuality. Therefore, the methodology of this study is characterized by having a descriptive type of research and is materialized through the collection of data from a script of interview via skype of the people involved. It appears that this issue is little explored, having few studies that deal with sexuality. It was concluded that people with physical disabilities had a positive perception of gender expression, denoting that want to be seen as people without any limitation and, above all, who are prepared to break the taboos that circumscribe their affective and social relations.

KEYWORDS: Special education. Physical disability. Sexuality.

\section{Introdução}

Partindo do pressuposto que a sexualidade é um tema que é resguardado de segredos e mitos, é preciso conceber que cada sujeito possui a própria expressão de sexualidade e, também, a diferenciação quando se trata da vida sexual. Diante disso, é preciso destacar o pensamento de Maia (2011, p.85) quando aborda que "a existência de ideias que são inverdades e, por isso, chamadas de mitos, existem para explicar fenômenos obscuros a partir de um discurso de um grupo dominante, que se julga superior, sobre um grupo de outras pessoas".

É importante frisar que o ser humano é marcado por desejos, erotismo e sentimentos de amor que o torna diferente dos demais seres humanos, porém há a peculiaridade de buscar em tal expressão uma forma de suprir as suas carências emocionais e afetivas. Neste sentido, quando tratamos da sexualidade para pessoas com deficiência, torna-se um campo estigmatizante, de forma que essas pessoas são tidas como assexuadas ou, até mesmo, desprovidas de qualquer desejo amoroso. Há de se destacar que o conceito de sexualidade deve ser concebido dialeticamente, de modo a abarcar um contexto amplo, crítico e histórico em detrimento de concebê-la somente ligada ao sexo e a genitália, pois "a sexualidade humana faz parte da expressão histórica

RIAEE - Revista Ibero-Americana de Estudos em Educação, Araraquara, v.12, n.4, p. 2177-2192, out./dez. 2017. 
da personalidade e é, essencialmente, cultural na medida em que sua expressão envolve a relação entre as pessoas num contexto social" (MAIA, 2011, p. 27).

Estudos que versam sobre a sexualidade na deficiência intelectual são comumente dissipados no âmbito do conhecimento, de modo a desmistificar o tabu que essas pessoas não possuem uma vida afetiva concreta e, por isso, são marginalizadas do seu contexto social (DENARI, 1997; PIECZKOWSKI, 2007; SANTOS, OSÓRIO, 2010; LITTIG. 2012). Portanto, quando se trata de sexualidade e deficiências, este assunto assume uma amplitude muito complexa que, muitas vezes, é marcada pelo desentendimento das potencialidades dessas pessoas em se relacionar com o outro, essencialmente com pessoas que não possuem deficiência.

Sobretudo no estudo de Denari (1997), é preciso analisar a falta de informações sobre sexualidade por parte das pessoas com deficiência intelectual, isso porque elas não foram instigadas a pensar sobre a sua própria sexualidade, ficando reféns da imagem preconceituosa que a sociedade tanto atribui a tais pessoas. Dessa forma, ora elas são considerados como anjos destacando uma concepção de coitados, e ora elas são considerados como feras pelo fato de não possuírem um comportamento correspondente aos padrões de normalidade no cerne de nossa sociedade.

Não obstante ao foco desses estudos serem na deficiência intelectual enquanto deficiência considerada mais alarmante no que concerne à expressão da sexualidade, a deficiência física também tem a sua situação de complexidade a partir do momento que modifica os estímulos sensitivos e motores. Isso porque, exemplificando, com a paraplegia, os estímulos neurosensoriais ficam comprometidos e alterados, e isso resulta em resignificar a visão de corpo, já que "o corpo dos paraplégicos, na região abaixo da lesão, é insensível à estimulação táctil, o que coloca algumas questões complexas diante do desejo sexual que persiste apesar das sequelas" (SILVA; ALBERTINI, 2007, p.38).

Importante destacar que a deficiência física é encarada como visível pelo fato da pessoa com essa deficiência normalmente fazer uso de uma cadeira de rodas (MAIA, 2006). Dessa forma, a visibilidade dessa deficiência pode ser concebida com um cunho de barreira enquanto um processo de aceitação da sociedade. Cabe, portanto, que a pessoa com deficiência torne tal visibilidade como um agregador positivo para a sua aceitação (e superação) no contexto social, ainda mais quando se lida com a temática da sexualidade.

Como o foco deste estudo é analisar tanto os homens como as mulheres, faz-se necessário considerar que cada gênero possui a sua expressão de sexualidade, ora 
marcada pela singularidade e ora pela significação que é dada para o relacionamento com outra pessoa. Destarte, o objetivo deste estudo é analisar o discurso das pessoas com deficiências físicas com lesão medular sobre a própria sexualidade.

Considerando que ambos os gêneros possuem as suas próprias expressões de sexualidade, eles se aproximam e também divergem quando se trata da deficiência física, isso porque

[...] na deficiência física, a visibilidade dessa condição, e suas consequências, podem ser exacerbadas, pois considerável parte dos sinais está corporificada na aparência, forma, tamanho e funcionalidade, denunciando a diferença. Lembramos que as experiências corporais ocorrem em e por particulares situações de vida e em um corpo socializado (MARTINS, BARSAGLINI, 2011, p. 111)

Dessa forma, faz-se necessário conceber que cada pessoa é singular e diferente, e a diferença também é marcada por mecanismos que a faz atuar de forma diferenciada em seu meio social. Contudo, isso não pode assumir um padrão de anormalidade versus normalidade, pois corre-se o risco de excluir a pessoa, bem como estigmatizar suas relações sociais, de modo que ela própria se sentirá excluída, deixando de vivenciar a sua sexualidade. Segundo Puhlmann (2000), a sexualidade se manisfeita por meio de regras e formas que têm a intencionalidade de controlar o impulso sexual. Pois, qualquer sujeito é submetido à pressão para se enquadrar aos padrões pré-concebidos de uma cultura e de uma ideologia sexual. Portanto,

[...] obviamente que as necessidades de uma pessoa deficiente física são diferentes das de uma pessoa dita normal. Assim como as necessidades de quem nasceu com a deficiência são diferentes das necessidades daqueles que adquirem a deficiência na juventude, ou na vida adulta. Também são diferentes as necessidades dos que estão no princípio da reabilitação daquelas que ocorrem depois de alguns anos, no que concerne ao tratamento da sexualidade (PUHLMANN, 2000, p. 20)

Foucault (2005) também anuncia esta situação ao descrever a realidade adversa e excludente vivenciada por uma gama de pessoas, nos meados da era clássica, que eram discriminadas do âmbito social, ficando aprisionadas em internatos e instituições especiais normalizadoras.

Diante do exposto, por meio de um histórico estigmatizante, quando se trata de sexualidade, as pessoas com deficiências são vistas como omissas ou, até mesmo, 
assexuadas, isso porque ainda é um imperativo o preconceito da sociedade perante essas pessoas.

Como forma de melhor compreender o estudo, algumas perguntas são importantes: Como se constitui a noção de sexualidade para esse grupo de pessoas? Qual é a concepção de sexualidade para as pessoas com deficiências física após lesão medular? Considerando que cada lesão possui a sua peculiaridade, quais são os anseios ou inquietações que essas pessoas têm diante da sexualidade?

Importante salientar que a sexualidade das pessoas com e sem deficiência no decorrer da vida terão os seus aspectos orgânicos alterados, por isso

Seria injusto generalizar, rotular e estigmatizar quem é a pessoa com deficiência - seus potenciais e seus limites - em função de rótulos, sem considerar o contexto social, econômico, educacional em que o sujeito se desenvolve e sem considerar a diversidade entre as pessoas com deficiências (MAIA; RIBEIRO, 2010, p. 160).

Acima de tudo, os padrões de normalidade são vistos como corretos quando se trata da temática de sexualidade, de modo que são construídas normas e regras idealizadas e tidas como corretas para serem seguidas, e tudo que foge da regra é visto como não-normal.

Nesse sentido, os temas subjacentes à sexualidade, como beleza, concepção de deficiência, desejo, gênero, saúde, desempenho físico, são concepções construídas socialmente e que podem ser diferenciados de acordo com determinada cultura. Essas concepções são concebidas como regras e normas que, segundo Foucault (1988) direcionam o que não devemos e o que devemos fazer no bojo de comportamentos e sentimentos sexuais e, por isso, se tornam repressivas e normativas.

\section{Metodologia}

Este estudo configura-se como uma pesquisa qualitativa de modo a possibilitar entendimento aprofundado sobre o objeto de estudo. Para responder ao objetivo proposto, acolhe-se ao tipo de pesquisa descritiva, pois, segundo Gil (2002), este procedimento possibilita averiguar as características de determinada população/grupo ou de um fenômeno, de forma que possa levantar opiniões, atitudes e crenças desse grupo, almejando desvendar as contradições e conflitos presentes no fenômeno estudado. Uma de suas peculiaridades está na utilização de técnicas padronizadas de coleta de dados, como por exemplo questionário ou até mesmo observação sistemática. 
Os participantes deste estudo serão $10(\mathrm{dez})$ pessoas com deficiências com lesão medular, entre elas 5 (cinco) homens e 5 (cinco) mulheres, tendo em vista que cada uma delas possui uma peculiaridade na sua lesão medular, cabendo, portanto, serem analisados os dados de forma peculiar, respeitando a singularidade dos(as) participantes.

Os dados foram coletados por meio da entrevista via Skype, na qual foi analisado o discurso das pessoas com deficiência física sobre as temática de sexualidade e deficiência física, bem como aplicada uma entrevista com vistas a elucidar a análise dos dados coletados.

Dessa forma, houve um contato inicial com a comunidade do Facebook "Cadeirantes também AMAM", que tem quase 10 mil membros. Os critérios para a seleção foram os membros mais assíduos da comunidade, que totalizam por volta de 100 membros pelas postagens. Deste modo, randomicamente, foram selecionados 10 participantes, sendo 5 (cinco) homens e 5 (cinco) mulheres, entre aqueles/as que se dispuseram a participar do estudo. Posteriormente, foram então efetuados os contatos, individualmente (inbox), e enviados os termos de consentimento e livre esclarecimento para serem assinados e devolvidos escaneados. Por fim, com a confirmação deste grupo de participantes, teve início a fase de entrevistas, via Skype, utilizando o software MP3 Recorder.

Para tanto, foi utilizada uma entrevista com um caráter coletivo, cujo objetivo é analisar as percepções, sentimentos, atitudes e ideias de determinado grupo sobre determinado assunto ou tema (GIL, 2007). As entrevistas são muito utilizadas com profundidade nas ciências humanas e sociais, no bojo de uma sistematização que permite a obtenção de dados no que concerne aos mais variados aspectos da vida social.

Enquanto análise de dados, a entrevista foi aplicada por meio de um roteiro de forma individual, em que as pessoas com deficiências responderam ao que foi solicitado em tempos diferentes. Importante ressaltar a importância do mediador na articulação das entrevistas com os participantes, isso porque elas ocorreram de forma desarticulada, na qual os participantes poderão responder à entrevista conforme os seus conhecimentos, anseios e inquietações.

\section{Resultados e discussão}

Neste tópico será discutido o discurso das pessoas com deficiências físicas sobre a própria sexualidade com vistas a explicitar, da forma mais profícua, como essas 
pessoas lidam como o próprio corpo e, sobretudo, explicitam a concepção de sexualidade. Para tanto, se faz necessário entender como essas pessoas redescobriram os seus corpos com o intuito de romperem o tabu de que são assexuadas ou, até mesmo, não tem uma expressão de sexualidade consolidada.

Por questões éticas, neste estudo, foram utilizados nomes fictícios para indicar os(as) participantes e os enunciados por eles produzidos. No que concerne às características de cada participante, a tabela 1 elucida alguns dados:

Tabela 1: Características dos(as) participantes

\begin{tabular}{|c|c|c|c|c|}
\hline Cadeirante & $\begin{array}{l}\text { Faixa } \\
\text { Etária }\end{array}$ & $\begin{array}{c}\text { Status de } \\
\text { relacionamento }\end{array}$ & Causa & Filhos \\
\hline João & $36-40$ & Solteiro & Acidente de carro & Não \\
\hline Paulo & $36-40$ & Namorando & Acidente de moto & Não \\
\hline Pedro & $50-55$ & Casado & $\begin{array}{l}\text { Perfuração por arma } \\
\text { de fogo }\end{array}$ & não \\
\hline Miguel & $26-30$ & Casado & Acidente de moto & $\operatorname{Sim}(2)$ \\
\hline Tomás & $36-40$ & Casado & $\begin{array}{l}\text { Perfuração por arma } \\
\text { de fogo }\end{array}$ & $\operatorname{Sim}(1)$ \\
\hline Rosa & $22-25$ & Solteiro & Acidente de carro & Não \\
\hline Margarida & $36-40$ & Casada & Acidente de carro & $\operatorname{Sim}(2)$ \\
\hline Hortência & $36-40$ & Namorando & Acidente de carro & Não \\
\hline Violeta & $26-30$ & Casada & Distrofia muscular & $\operatorname{Sim}(1)$ \\
\hline Dália & $18-21$ & Namorando & Acidente de moto & Não \\
\hline
\end{tabular}

Fonte: Elaboração própria (2016)

Importante frisar que um dos dilemas que as pessoas com deficiência física têm que lidar com o senso comum é sobre a possibilidade ou não de ter filhos. Não obstante ter uma pergunta específica para tratar deste assunto, alguns participantes relataram ter filhos, a saber, os cadeirantes Pedro, Miguel, Tomás, Margarida e Violeta, de modo a cunhar um pensamento otimista de que qualquer cadeirante pode ter filhos, sobretudo por causa do avanço da tecnologia que possibilita a ascensão de técnicas modernas de inseminação artificial. Maia e Ribeiro (2010) elucidam que as pessoas com deficiências 
podem ou não ter filhos/as, pois estão ligadas às questões hereditárias, sendo um fator orgânico essencial para a possibilidade de ter filhos.

Com isso, quando os(as) participantes foram questionados(as) se a deficiência física é um empecilho para tratar sobre a sexualidade, por um lado, um grupo se posicionou no sentido de que não há problema nenhum a pessoa ter deficiência física e falar sobre sexualidade, pois é uma característica intrínseca da pessoa. E, por outro lado, um grupo se posicionou no sentido de que cada pessoa tem a sua própria expressão de sexualidade e, portanto, torna-se imperativo que cada pessoa possa difundir os conhecimentos que se fazem presentes nas suas lesões medulares.

Considerando que a sexualidade das pessoas com deficiências, especialmente a física, é encarada como um tabu ou com um caráter de senso comum, os participantes foram indagados se sentem seguros para falar sobre sexualidade. A maioria dos participantes se posicionou como seguros para falar sobre sexualidade, como pode ser analisado no enunciado:

Sim, da minha parte sim. No início da lesão é difícil, você tem vergonha de falar sobre qualquer coisa, até mesmo porquê você está na cadeira de rodas e também sobre o que aconteceu (João).

Importante destacar que as respostas das entrevistas coadunaram com o conceito de sexualidade com a finalidade de ir além do biológico, não obstante ela ser intrinsecamente de cunho biológico, isso porque a expressão da sexualidade pode significar a busca pelo prazer manifestado por estímulos que resultam do sistema nervoso central.

Nesse sentido, urge complementar tal pensamento com o discurso da Margarida, que elucida:

Sim sinto, sexualidade é carinho, respeito, carícia e penetração, é tudo aquilo que faz bem e que dá prazer, isso é sexualidade, no caso um simples abraço. (Margarida).

É possível analisar que os discursos dos cadeirantes supracitados estão enraizados de um valor positivo e marcados por relações de poder que denotam que o discurso não é neutro, pois está imbuído de um caráter dinâmico. Os enunciados anteriores só acentuam que as pessoas com deficiência física querem ser ouvidas, bem como expressarem que são pessoas que têm uma vida sexual ativa, sobretudo porque estão seguras para falar sobre sexualidade. Equivocadamente, algumas pessoas pensam que os lesados medulares não têm uma expressão da sexualidade, já que isso resulta em

RIAEE - Revista Ibero-Americana de Estudos em Educação, Araraquara, v.12, n.4, p. 2177-2192, out./dez. 2017. 
um processo de preconceito, considerando que muitos deles só concebem a sexualidade enquanto sexo, somente.

Considerando que a maioria dos participantes está em um relacionamento sério ou casado(a), quando questionados para falarem um pouco sobre o relacionamento, os(as) participantes demonstraram estar abertos(as) e solícitos(as) para construir um discurso que seja otimista e, grosso modo, que não deixassem os problemas e as dificuldades influenciarem na resposta. Dessa forma, os participantes esboçaram um discurso transparecendo em seu enunciado um padrão de normalidade, de modo a cunhar um sentido de igualdade perante as pessoas que não possuem deficiência, como, por exemplo:

\section{[...] nosso relacionamento é normal como todos os casais apaixonados, sem preconceito e aceitação (Violeta).}

Ainda, pode ser verificado a seguir:

No relacionamento afetivo, nós dois somos de igual. Mudou pouca coisa assim, foram os limites já que qualquer ser humano têm seus limites e eu também tenho os meus. Mas, nossa relação afetiva ficou normal mesmo, não como era antes, porém de uma forma diferente (Miguel).

Conforme os discursos nos enunciados supracitados, as pessoas com deficiência física querem ser tratadas como iguais em um relacionamento afetivo, considerando que cada pessoa tem a sua peculiaridade e singularidade em um relacionamento. Tal pensamento ressalta que essas pessoas têm uma vida sexual ativa e, por sua vez, querem ser tratadas como seres humanos que também têm as suas experiências atinentes à sexualidade.

Nesse sentido, pautando em Foucault (2001), cria-se o binarismo entre 'normais' e 'anormais', em que os 'normais' são aquelas que estão dentro das regras préestabelecidas na sociedade, ao passo que os 'anormais' são considerados aqueles desviantes de tais regras (re)criadas pela sociedade. Diante disso, as pessoas com deficiência física devem ter valorizadas as suas singularidades, isso porque ser normal ou anormal está intrinsecamente ligado ao conhecimento de mundo que cada pessoa traz consigo, sobretudo porque cada pessoa possui necessidades que vão além das limitações, cor de pele e condição financeira. Isso porque é preciso ter uma visão ampliada da potencialidade dessas pessoas se relacionarem sexual e afetivamente, já que 
"a negação da sexualidade das pessoas com deficiências físicas ocorre a partir de uma visão fragmentada do corpo perfeito" (MAIA, 2006, p. 174).

Diante desse panorama, também existem cadeirantes que se sentem inseguros(as) sobre sexualidade no início do relacionamento, isso porque eles têm que conhecer o corpo novamente e explicitar tais mudanças para o seu companheiro(a). Tal perspectiva pode ser acompanhada no registro da Hortência:

Tenho namorado sim, temos uma relação bem tranquila, mas tenho bastante dificuldade no início do namoro até me adaptar com a pessoa (Hortência).

Quando os participantes foram indagados se há alguma alteração no corpo no que concerne à sexualidade, a maioria deles relatou que realmente o corpo sofre algumas modificações que têm um caráter físico ou orgânico. Nesse sentido, eles relataram que é preciso ter uma nova redescoberta do corpo, como pode ser confirmado no discurso do João:

Olha... eu acho que apesar de você estar na cadeira de roda, a primeira coisa que vem são as mulheres, como é que eu vou fazer, como é que eu vou redescobrir de novo, porque você tem que reconhecer o seu corpo novamente. Você tem que aprender tudo de novo, você tem que reeducar o seu corpo para tudo, e agora eu não vou fazer mais nada, se a mulher chegar até mim como eu vou fazer, $e$ agora? (...) Acho que é isso que limita as coisas para não falar sobre isso, praticamente a vergonha, não tem disponibilidade de falar qualquer assunto porque a pessoa fica com receio né. A pessoa diz assim: o que será que ele vai me responder? O que será que a pessoa vai pensar quando eu perguntar isso para ela? Eu também era assim no começo, eu ficava com medo, falei assim aiaiaiai...o que a pessoa vai responder para mim, o que eu vou saber sobre isso. Ai com o tempo você vai vendo que não é esse bicho de sete cabeças. (João)

Por meio do enunciado supracitado, João relatou as dificuldades enfrentadas no início da lesão medular, que perpassaram por um pensamento de medo de encarar a nova situação que foi imposta e, sobretudo, exposta, de modo a criar um mecanismo de defesa com o intuito de não sofrer com tal situação. Com isso, se faz necessário criar pontes de união de conhecimentos por meio de uma equipe multiprofissional que possa orientar as pessoas com deficiência física sobre a própria sexualidade e, assim, possibilitar caminhos de intervenção para um acompanhamento contínuo e eficaz.

Devido ao entendimento de que o corpo sofre alterações nas pessoas com deficiência física, alguns participantes coadunaram com o pensamento do porquê muitas pessoas têm dificuldades para falar sobre sexualidade, pois a concepção de homem que

RIAEE - Revista Ibero-Americana de Estudos em Educação, Araraquara, v.12, n.4, p. 2177-2192, out./dez. 2017. 
muitas pessoas têm dos cadeirantes é, por si só, equivocada e negativa. Desse modo, os(as) cadeirantes são encarados como "coitadinhos", bem como aquelas pessoas que "vegetam" e que não possuem um papel atuante na sociedade. No relato de Paulo é possível perceber que a sexualidade é vista como um tabu, por isso a dificuldade de falar sobre tal assunto

Porque ao longo dos anos isso ainda é um tabu ainda, é uma coisa meia, devido a questão educação, da intimidade, a sexualidade é uma coisa reservada, apesar hoje da grande mídia as coisas vem mudando bastante (Paulo).

Além disso, no discurso dos(as) participantes ficou nítido o sentimento de uma imagem estigmatizada sobre a sexualidade das pessoas com deficiência física, isso porque elas são vistas com um caráter de 'coitadização', ou seja, não são vistas como pessoas que têm um papel determinante na sociedade e, por sua vez, devem estar submissos aos interesses de outras pessoas. Portanto, "o processo de construção da imagem corporal, quando se trata da pessoa com deficiência física, resulta, na maioria dos casos, na percepção de um corpo desvantajoso, em relação aos outros não deficientes" (MAIA, 2011, p. 55).

Acima de tudo, a concepção de corpo explicitada pelos cadeirantes denota um sentido biológico ligado às questões orgânicas no que tange a encarar a redescoberta do corpo enquanto um processo referente à limitação e ao defeito. Para tanto, urge repensar sobre o conceito de deficiência atrelado à sexualidade, pois tal processo exige que a deficiência seja encarada como um fenômeno socialmente construído em detrimento de encará-la tão somente como um questão médica e orgânica (MAIA, 2006, 2010).

No que concerne ao processo de reabilitação com vistas a apresentar a expressão da sexualidade, a maioria dos(as) participantes relatou que passou por um curso em centro de reabilitação de modo a aprender um pouco mais como se processa a sexualidade das pessoas com deficiência física.

Com isso, eles/elas tiveram nesse curso a instrução de uma sexóloga, que ministrou sobre aspectos essenciais como, por exemplo, a sensibilidade, a redescoberta do corpo, bem como a readaptação do organismo. Há de se destacar a ínfima quantidade de produções que versam sobre sexualidade e deficiência física, por isso os(as) participantes buscaram outros meios comunicacionais para se instruir sobre o papel da sexualidade para cadeirantes, como blogs e artigos na internet. Tal pensamento pode se verificado no enunciado de Margarida e de João: 
Fui reabilitada no Sarah Kubistchek e lá eles orientam direitinho, e eu também procurei conhecer mais através da internet, através de blogs e de grupos que trabalham sobre isso (Margarida).

Sim, tive contatos com psicólogos na época do acidente que me ajudou muito, fui para o Sarah Kubitschek em Brasília, lá a gente aprende a se adaptar a um novo modo de vida que a deficiência impõe, a gente aprende novas maneiras (João).

Não obstante o avanço da tecnologia por meio de informações que sejam profícuas para informar sobre sexualidade, dois participantes não participaram de aulas ou não foram orientados sobre sexualidade nas instâncias de reabilitação, conforme o discurso de Pedro e Hortência:

Sobre a orientação médica eu nunca tive orientação, até porque eu adaptei muito fácil e muito rápido a essa vida. Dai eu sou um pouco custoso, eu já adiantei em certas coisas [...] E no centro de reabilitação eu não tive nenhuma orientação sobre sexualidade (Pedro).

Não tive essa reabilitação, nem mesmo recomendação médica. Fui me adaptando sozinha, comigo mesma e com a pessoa com quem me relacionava (Hortência).

O desconhecimento no que concerne à reabilitação sexual pode levar a pessoa com deficiência física a sentir desinteresse em se relacionar com outra pessoa, sobretudo porque "a falta de esclarecimentos dos profissionais da saúde aos pacientes sobre as questões da sexualidade é comum em várias áreas e não somente nos profissionais que trabalham na reabilitação de pessoas com deficiência física” (MAIA, 2006, p 198). Por outro lado, é preciso construir uma postura otimista e ampla, por meio de atitudes que promovam uma reabilitação coesa e consciente para essas pessoas, seja por mecanismos de informação que possam estimulá-las a terem uma vida independente e desprovida de qualquer preconceito.

Considerando que é propagada uma cultura de corpo perfeito e, por sua vez, de um modelo de imagem corporal a ser seguido, quando os(as) participantes foram questionados se a mídia influencia na sexualidade das pessoas com deficiência física, o discurso predominante foi que quase não é abordado sobre essas temáticas na mídia, como forma de (des)mascarar como se processa a sexualidade de tais pessoas. Conforme pode ser analisado no enunciado de Margarida:

RIAEE - Revista Ibero-Americana de Estudos em Educação, Araraquara, v.12, n.4, p. 2177-2192, out./dez. 2017. 
Quando a mídia apresenta alguma coisa sim, mas eu vejo muito pouco ou quase nada sobre mídia, com certeza se divulgar alguma coisa vai influenciar sim para bem ou não, eu acho o que falta é divulgação, teria que divulgar muito mais (Margarida).

Importante destacar no discurso acima que a mídia realiza uma seleção do que será abordado nos meios midiáticos, como forma de propagar o que é aceito socialmente e, sobretudo, direcionando o que a população deve saber enquanto verdade. Infelizmente, nesta amálgama de discursos e práticas equivocadamente dissipados por tais meios, as pessoas com deficiência física são culturalmente reféns de um modelo de sociedade que instiga o disciplinamento de práticas atreladas ao consumo e a perfeição, normalmente acentuada por mecanismos de controle que circunscrevem uma biopolítica para tal sociedade.

Assim, com o intuito dos participantes deixarem uma mensagem para a finalização das entrevistas, tal intencionalidade foi esboçada para que eles se tornem protagonistas da própria por meio de uma mensagem que queiram deixar para as outras pessoas.

Eu diria assim, aquelas pessoas que ficam enclausuradas, que busquem conhecer o mundo lá fora, busquem conhecer outras pessoas, trocas experiências, trocas ideias, porque é isso que nos faz crescer. A vida continua, pois, você só está em cima de uma cadeira de rodas, e mais uma coisa quanto mais você resiste, quanto mais você refugia, o sofrimento é maior (Margarida).

O que eu poderia falar para todo mundo, é que perdessem o medo, que procurassem saber aquilo que tem vontade. Porque hoje em dia tudo tem explicação, tem pessoas que estão dispostos ali para ajudar, a explicar que alguma coisa que o cadeirante ou lesado medular, seja novato ou tenha uma lesão a pouco tempo [...] Se a pessoa tiver vontade e quiser saber, pode ter certeza que ela vai chegar na resposta que ela está procurando. Hoje em dia as pessoas estão mais instruídas (João).

A ênfase dos enunciados perpassou pela aceitação da sexualidade dessas pessoas, com vistas a perderem o medo para tratar sobre tal sexualidade, bem como para que tais pessoas sejam vistas como sexuadas e que sejam quebrados os tabus de que elas não tem vida sexual ativa.

\section{Considerações finais}


O pressuposto de que a sexualidade das pessoas com deficiência física é tido como um tabu não foi constatado neste grupo de participantes, pois eles querem ser considerados, no que tange à expressão da sexualidade, como pessoas ditas 'normais'. Quiça o tabu seja direcionado para as pessoas que não têm deficiência, já que pode resultar em um processo de distanciamento e, até mesmo, de preconceito, ou seja, a percepção das outras pessoas pode estar equivocada, considerando que as próprias pessoas com deficiência física revereciam como sexuadas e potenciais para constituírem família.

Sobretudo perante os resultados analisados, destaca-se que as pessoas com deficiência física explicitam um discurso que coaduna com o pensamento de otimismo e, também, a predominância do discurso biológico na expressão do corpo. Tal discurso é comum para pessoas que possuem alguma deficiência, pois o corpo sofre alterações que dificultam uma gama de fatores sensitivos e motores, fazendo com que elas executem um processo de redescoberta do corpo. Contudo, tal processo é dito somente sob o prisma da ausência, em que muitas dessas pessoas se privam de relacionar com outra pessoa.

Acima de tudo, partindo do pressuposto da influência dos centros de reabilitação e da mídia, os(as) participantes deixaram explícitos o sentido de busca pelo conhecimento como forma de contornar as carências de informações no tocante à sexualidade. Importante frisar nos discursos dos(as) entrevistados(as) que o apoderamento sobre a expressão da sexualidade começa pelo protagonismo da própria pessoa com deficiência física com o intuito de melhor se informar sobre o assunto e, também, se sentir bem com o próprio corpo.

Assim, faz-se necessário que outros estudos abordem a realidade das pessoas com deficiência, sobretudo a deficiência física, no que tange em abordar a temática da sexualidade, tendo em vista que tal tema é pouco explorado pela literatura, por se tratar de um assunto que denota uma questão paradigmática e de ruptura de valores. Portanto, este estudo pode ser considerado um começo para que a voz das pessoas com deficiência física possa ser ouvida, cuja conjectura é explicitar o protagonismo dessas pessoas no tocante à expressão da sexualidade, bem como na forma de se expressar corporalmente.

\section{REFERÊNCIAS}

RIAEE - Revista Ibero-Americana de Estudos em Educação, Araraquara, v.12, n.4, p. 2177-2192, out./dez. 2017. 
DENARI, F. E. Adolescência, afetividade, sexualidade e deficiência intelectual: o direito ao ser/estar. Revista Ibero-Americana de Estudo em Educação, v. 5, n. 1, 2010 .

FOUCAULT, M. História da sexualidade: a vontade de saber. São Paulo: Graal, 1988.

FOUCAULT, M. Os anormais. Curso no Collége de France (1974-1975). Tradução:

Eduardo Brandão. São Paulo: Martins Fontes, 2001.

FOUCAULT, M. História da loucura na idade clássica. $8^{a}$ ed. São Paulo: Perspectiva, 2005.

GIL, A. C. Como elaborar projetos de pesquisa. $4^{\text {a }}$ ed. São Paulo: Atlas, 2002.

GIL, A. C. Métodos e técnicas de pequisa social. 5a ed. São Paulo: Atlas: 2007.

LITTIG, P. M. C. B. et al. Sexualidade na deficiência Intelectual: uma análise das percepções de mães de adolescentes especiais. Revista Brasileira de Educação Especial, Marília, v. 18, n. 3, p. 469-486, jul./set. 2012.

MAIA, A. C. B. Sexualidade e deficiências. São Paulo: Editora Unesp, 2006.

MAIA, A. C. B. Sexualidade e deficiência física: questões sociais sobre o corpo e o erotismo. In: TEIXEIRA, F (Org.). Sexualidade e educação sexual: políticas educativas, investigação e práticas. Milho: e-book, 2010, p. 103-108.

MAIA, A. C. B. Inclusão e sexualidade: na voz de pessoas com deficiência física. Curitiba: Juruá, 2011.

MAIA, A. C. B.; RIBEIRO, P. R. M. Desfazendo mitos para minimizar o preconceito sobre a sexualidade de pesssoas com deficiências. Revista Brasileira de Educação Especial, Marília, v. 16, n. 2, p. 159-176, maio/ago. 2010.

MARTINS, J. A.; BARSAGLINI, R. A. Aspectos da identidade na experiência da deficiência física: um olhar socioantropológico. Interface - Comunicação, Saúde, Educação, Botucatu, v. 15, n. 36, p. 109-21, jan./mar. 2011.

PIECZKOWSKI, T. M. Z. Educação Sexual da Pessoa com Deficiência Mental. Revista Educação Especial, Santa Maria, n. 30, p. 211-226, 2007.

PUHLMANN, F. A Revolução Sexual sobre rodas- conquistando o afeto e a autonomia. São Paulo: O nome da Rosa, 2000.

SANTOS, M. W. V. dos; OSÓRIO, A. C. do N. Saber e prática na constituição da sexualidade da pessoas com deficiência mental. Revista Educação Especial, Santa Maria, v. 23, n. 36, p. 117-130, jan/abr. 2010.

SILVA, L. C. A.; ALBERTINI, P. A reinvenção da sexualidade masculina na paraplegia adquirida. Revista do Departamento de Psicologia, UFF, v. 19, n. 1, p. 37 48, jan./jun. 2007. 


\section{Como referenciar este artigo}

SOUZA, Calixto Júnior de.; DENARI, Fátima Elisabeth.; COSTA, Maria da Piedade Resende da. O discurso das pessoas com deficiência física sobre a própria sexualidade. Revista Ibero-Americana de Estudos em Educação, Araraquara, v. 12, n. 4, p. 2177 2192 out./dez. 2017. Disponível em: <http://dx.doi.org/10.21723/riaee.v12.n4.out./dez.2017.9123>. E-ISSN: 1982-5587.

Submetido em: 13/12/2016

Aceito em: 02/07/2017 